\title{
Design and optimization of axial flux brushless DC motor dedicated to electric traction
}

\author{
Mariem Ben Amor ${ }^{1}$, Souhir Tounsi², Mohamed Salim Bouhlel ${ }^{3}$ \\ ${ }^{1}$ National School of Engineers of Sfax (ENIS), Sfax University, SETIT Research Unit, Sfax, Tunisia \\ ${ }^{2}$ National School of Electronics and Telecommunications of Sfax, Sfax University, SETIT Research Unit, Sfax, Tunisia \\ ${ }^{3}$ Higher Institute of Biotechnology of Sfax (ISBS), Sfax University, SETIT Research Unit, Sfax, Tunisia \\ Email address: \\ souhir.tounsi@isecs.rnu.tn (S. Tounsi), medsalim.bouhlel@enis.rnu.tn (M. S. Bouhlel)
}

\section{To cite this article:}

Mariem Ben Amor, Souhir Tounsi, Mohamed Salim Bouhlel. Design and Optimization of Axial Flux Brushless DC Motor Dedicated to Electric Traction. American Journal of Electrical Power and Energy Systems. Special Issue: Design, Optimization and Control of Electric Vehicles: (DOCEV). Vol. 4, No. 2-1, 2015, pp. 42-48. doi: 10.11648/j.epes.s.2015040201.16

\begin{abstract}
In this paper, we present an analytic model of the whole motor converter taking in account of several systemic and physical constraints. Being couple to a model of the losses of the power chain and to a model of the mass of the motor, this analytic model puts a problem of conjoined optimization of the consumption and the cost of the motor. This problem is solved by genetic algorithms method.
\end{abstract}

Keywords: Electric Vehicle, Motor, Electromagnetic Converter, Design, Optimization

\section{Introduction}

Currently and in look of the strong petroleum crises, during these last decades and the problems of atmospheric pollution, the electrification of vehicles project became a project of actuality. In this context, several works of research are thrown on this thematic [1], [2], [3], [4] and [5].

The electric vehicle production in big series is braked by their elevated cost as well as their weak autonomy. In this context, a modular axial motor structure and with permanent magnet reducing the cost of manufacture is chosen.

We choice the analytic method to conceive the whole motor converter seen its compatibility to optimization approaches. Indeed, it's fast and product results quickly and without iterations.

The coupling of power train losses model and the model of the motor mass to the program dimensioning the motor converter, pose an optimization problem. This last is solved by the software of optimization based on the Genetic Algorithm method.

\section{Structures of the Traction Motor}

\subsection{Manufacturing Cost Reduction}

The motor structure is modular i.e. it can be with several stages. This technology allows the reduction of the production cost of these motor types. The slots are right and open what facilitates the coils insertion and reduces the motor manufacturing cost. The concentrated winding is used because of its advantages:

- Reduction of the manufacturing time of this motor (insertion of coils in one block).

- Reduction of the end-windings.

- Reduction of the motor bulk.

Figure 1 illustrates the first trapezoidal configuration $(n=1)$ with axial flux only one stage [6].
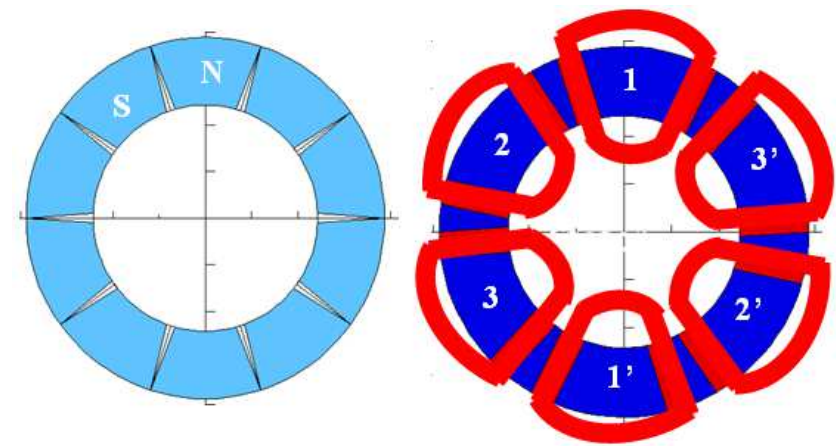

Figure 1. 5 pairs of poles, 6 main teeth, axial flux and trapezoidal configuration.

Five configurations with a trapezoidal wave-form are found while being based on optimization rules of the ripple torque 
and cost. Each configuration is characterized by a variation law of the pole pairs number (p) according to an integer number $\mathrm{n}$ varying from one to infinity, the ratio $(\mathrm{r})$ of the number of main teeth $\left(\mathrm{N}_{\mathrm{t}}\right)$ by the number of pole pairs, the ratio $(v)$ between the angular width between two main teeth and that of a principal tooth, the ratio $(\alpha)$ between the angular width of a principal tooth and that of a magnet and the ratio $(\beta)$ between the angular width of a magnet and the polar step. Table .1 gives these ratios for these configurations [6], [7], [8], [9].

Table 1. Found configurations

\begin{tabular}{llllll}
\hline $\begin{array}{l}\text { Trapezoidal } \\
\text { configurations }\end{array}$ & $\mathbf{p}$ & $\mathbf{r}$ & $\boldsymbol{v}$ & $\alpha$ & $\beta$ \\
\hline 1 & $2 . \mathrm{n}$ & 1.5 & $1 / 3$ & 1 & 1 \\
2 & $5 . \mathrm{n}$ & 1.2 & $2 / 3$ & 1 & 1 \\
3 & $7 . \mathrm{n}$ & $6 / 7$ & $4 / 3$ & 1 & 1 \\
4 & $4 . \mathrm{n}$ & 0.75 & $5 / 3$ & 1 & 1 \\
5 & $5 . \mathrm{n}$ & 0.6 & $7 / 3$ & 1 & 1 \\
\hline
\end{tabular}

\subsection{Converter Continuous Voltage}

The motor constant is defined by [9]:

$$
\mathrm{K}_{\mathrm{e}}=2 \times \mathrm{n} \times \mathrm{N}_{\mathrm{s}} \times \mathrm{A} \times \mathrm{B} \times \mathrm{B}_{\mathrm{g}}
$$

For the axial flux structures $\mathrm{A}$ and $\mathrm{B}$ are given by:

$$
\begin{aligned}
& \mathrm{A}=\frac{\mathrm{D}_{\mathrm{e}}-\mathrm{D}_{\mathrm{i}}}{2} \\
& \mathrm{~B}=\frac{\mathrm{D}_{\mathrm{e}}+\mathrm{D}_{\mathrm{i}}}{2}
\end{aligned}
$$

Where $D_{e}$ and $D_{i}$ are respectively the external and the internal diameter of the axial flux motor, $\mathrm{N}_{\mathrm{s}}$ is the number of spire per phase, $\mathrm{n}$ is the module number and $\mathrm{B}_{\mathrm{g}}$ is the flux density in the air-gap.

The converter's continuous voltage $\mathrm{U}_{\mathrm{dc}}$ is calculated so that the vehicle can function at a maximum and stabilized speed with a weak torque undulation. The electromagnetic torque that the motor must exert at this operation point, via the mechanical power transmission system $\mathrm{T}_{\mathrm{Udc}}$ (reducing + differential) is estimated by the following expression:

$$
\mathrm{T}_{\mathrm{Udc}}=\frac{\mathrm{P}_{\mathrm{f}}}{\Omega}+\mathrm{T}_{\mathrm{d}}+\left(\mathrm{T}_{\mathrm{b}}+\mathrm{T}_{\mathrm{vb}}+\mathrm{T}_{\mathrm{fr}}\right)+\frac{\mathrm{T}_{\mathrm{r}}+\mathrm{T}_{\mathrm{a}}+\mathrm{T}_{\mathrm{c}}}{\mathrm{r}_{\mathrm{d}}}
$$

Where $T_{b}$ is the rubbing torque of the motor, $T_{v b}$ is the viscous rubbing torque of the motor, $T_{\mathrm{fr}}$ is the fluid rubbing torque of the motor, $\mathrm{T}_{\mathrm{r}}$ is the torque due to the friction rolling resistance, $T_{a}$ is the torque due to the aerodynamic force, $T_{c}$ is the torque due to the climbing resistance, $T_{d}$ is the reducer losses torque and $\mathrm{P}_{\mathrm{f}}$ are the iron losses and $\Omega$ is the motor angular speed.

At this operation point, the phase current is given by the following relation:

$$
\mathrm{I}_{\mathrm{p}}=\frac{\mathrm{T}_{\mathrm{Udc}}}{\mathrm{K}_{\mathrm{e}}}
$$

The only possibility making it possible to reach the current value $I_{p}$ with a reduced undulation factor $(10 \%$ for example) is to choose the converter's continuous voltage solution of the following equation [7]:

$$
\mathrm{r}=\frac{\mathrm{t}_{\mathrm{m}}}{\mathrm{t}_{\mathrm{p}}}=10 \%
$$

Where $t_{p}$ is the phase current maintains time at vehicle maximum speed and $t_{m}$ is the boarding time of the phase current from zero to $I_{p}[9]$ :

$$
\mathrm{t}_{\mathrm{m}}=-\frac{\mathrm{L}}{\mathrm{R}} \times \ln \left(1-\frac{2 \times \mathrm{R} \times \mathrm{I}_{\mathrm{p}}}{\mathrm{U}_{\mathrm{dc}}-\mathrm{K}_{\mathrm{e}} \times \Omega_{\text {max }}}\right)
$$

Where $\mathrm{R}$ and $\mathrm{L}$ are respectively the phase resistance and inductance and $\Omega_{\max }$ is the maximum angular velocity of the motor.

The phase current maintains time at maximum speed of vehicle (corresponds to 120 electric degrees) is given by the following formula [9]:

$$
\mathrm{t}_{\mathrm{p}}=\frac{1}{3} \times \frac{2 \times \pi}{\mathrm{p} \times \Omega_{\max }}
$$

The converter's continuous voltage takes the following form:

$$
\mathrm{U}_{\mathrm{dc}}=\frac{2 \times \mathrm{R} \times \mathrm{I}_{\mathrm{p}}}{1-\exp \left(-\frac{2 \times \pi \times \mathrm{r}}{3 \times \mathrm{p} \times \Omega_{\text {max }} \times \frac{\mathrm{L}}{\mathrm{R}}}\right)}+\mathrm{K}_{\mathrm{e}} \times \Omega_{\max }
$$

The phase inductance of the all configurations is expressed as follows [9]:

$$
\mathrm{L}=\frac{3 \times \mu_{0}}{\mathrm{~N}_{\mathrm{t}}} \times\left(\frac{\mathrm{A}_{\mathrm{t}}}{\mathrm{g}+\mathrm{t}_{\mathrm{m}}}+\frac{\mathrm{A} \times \mathrm{h}_{\mathrm{s}}}{2 \times \mathrm{A}_{\mathrm{s}}}\right) \times \mathrm{N}_{\mathrm{s}}^{2}
$$

Where $\mu_{0}$ is the air permeability, $A_{t}$ is slot area, $t_{m}$ is the magnet thickness, $h_{s}$ is slot height, $g$ is the air-gap thickness and $\mathrm{A}_{\mathrm{s}}$ is the slot width.

The converter continuous voltage increases by increasing of the vehicle speed which validates the fact of calculating its value at maximum speed. Two important factors involving the increase of the converter continuous voltage:

- The increase of the motor electric constant.

- The reduction of the undulation factor.

Consequently, a compromise between the reduction of the converter continuous voltage directly related to the space reserved for the battery and the reduction of undulation factor is to be found. 


\subsection{Design Methodology}

We choose the analytic modelling of the motor, because it's compatible to the optimisations approaches [10], [11], [12], [13]. The analytic sizing step is inverted starting from needs (torque, motor velocity) towards geometry dimensions. While, in classical analytic sizing, the computation starts from geometry towards needs. Indeed the limit of the plan torque/velocity of the motor is given. The electrical motor has to be able to function in this plan without constraints. Here, the problem resolution is completely reversed. For example, the operating temperature is fixed and then computed. It should be also recognised that the inversion of the problem facilitates its resolution. In the same way, the designer fixes the induction. The worksheet includes 200 items of computed elements. The difficulty is to classify these elements and to distinguish results from data.

The worksheet computes the geometrical dimensions of rotor and stator as well as windings, temperature, inductance, leakages and efficiency for different operating points and control modes.

A sizing program is developed with equations detailed below. The program inputs are:

1. Electric vehicle specifications.

2. Materials properties.

3. Configuration, i.e. magnet number and teeth number.

4. Inner and outer diameter of the motor.

5. Notebook data.

6. Current density in coils $\delta$.

7. Rotor yoke $B_{\mathrm{ry}}$, stator yoke $\mathrm{B}_{\mathrm{sy}}$, flux density in the air-gap $B_{g}$, reducer ratio and number of spire per phase $N_{s}$.

When inputs 3 . and 4 . are set, magnet shapes, teeth and slots are fixed. Then, the area of one tooth $A_{t}$ and the average length of a spire $\mathrm{L}_{\mathrm{sp}}$ are calculated from geometric equations.

This model is validated by finite elements method. Indeed, the motor is drawn according to its geometrical magnitudes extracted from analytical model with the software Maxwell-2d, and is simulated in dynamic and static in order to compare the results obtained with those found by the analytical method.

The coupling of this model to a model evaluating the power train losses and motor mass, poses an optimization problem with several variables and constraints. This latter is solved by the genetic algorithms (GAs) method [10], [11], [12], [13].

\section{Dimensioning Torque}

The back electromotive force (E.m.f) stage level is given by the following expression [10], [11], [12], [13]:

$$
\mathrm{E}=\mathrm{n} \times \mathrm{N}_{\mathrm{s}} \times \mathrm{A} \times \mathrm{B} \times \Omega \times \mathrm{B}_{\mathrm{g}}
$$

The instantaneous electromagnetic power $\mathrm{P}_{\mathrm{e}}(\mathrm{t})$ is expressed by the following relation

$$
P_{e}(t)=\sum_{i=1}^{m} e_{i}(t) \times i_{i}(t)
$$

Where $e_{i}(t)$ and $i_{i}(t)$ are respectively the back electromotive force and the current of the phase $i$.

Two phases are fed simultaneously and the currents of phases have the same wave-form as the electromotive force with a maximum value of motor phase current I. Consequently, for a constant speed, the electromagnetic power developed by the motor takes the following form:

$$
\mathrm{P}_{\mathrm{e}}=2 \times \mathrm{E} \times \mathrm{I}
$$

The electromagnetic torque developed by the motor is expressed by:

$$
\mathrm{T}_{\mathrm{m}}=2 \times \frac{\mathrm{E} \times \mathrm{I}}{\Omega}
$$

The electromagnetic torque developed by the motor results [9]:

$$
\mathrm{T}_{\mathrm{m}}=2 \times \mathrm{n} \times \mathrm{N}_{\mathrm{s}} \times \mathrm{A} \times \mathrm{B} \times \mathrm{B}_{\mathrm{g}} \times \mathrm{I}
$$

The electromagnetic torque which the motor must develop so that the vehicle can move with a speed $\mathrm{v}$ is deduced from the dynamics fundamental relation related to the electric vehicle dynamic:

$$
\begin{aligned}
& \mathrm{T}_{\mathrm{m}}=\frac{\mathrm{P}_{\mathrm{f}}}{\Omega}+\mathrm{T}_{\mathrm{d}}+\left(\mathrm{T}_{\mathrm{b}}+\mathrm{T}_{\mathrm{vb}}+\mathrm{T}_{\mathrm{fr}}\right)+\frac{\mathrm{T}_{\mathrm{r}}+\mathrm{T}_{\mathrm{a}}+\mathrm{T}_{\mathrm{c}}}{\mathrm{r}_{\mathrm{d}}}+ \\
& \left(\frac{\mathrm{J}}{\mathrm{R}_{\mathrm{w}}}+\frac{\mathrm{M}_{\mathrm{v}} \times \mathrm{R}_{\mathrm{w}}}{\mathrm{r}_{\mathrm{d}}}\right) \times \frac{\mathrm{dv}}{\mathrm{dt}}
\end{aligned}
$$

Where $r_{d}$ is the reduction ratio, $M_{v}$ is the vehicle mass, $R_{w}$ is the vehicle wheel radius, $\mathrm{J}$ is the motor moment of inertia and $\mathrm{v}$ is the vehicle velocity.

The different torques are expressed by the following equations [14], [15], [16]:

$$
\begin{gathered}
\mathrm{T}_{\mathrm{b}}=\mathrm{s} \times \frac{\mathrm{v}}{|\mathrm{v}|} \\
\mathrm{T}_{\mathrm{vb}}=\chi \times \mathrm{v} \\
\mathrm{T}_{\mathrm{fr}}=\mathrm{k} \times \mathrm{v} \times|\mathrm{v}| \\
\mathrm{T}_{\mathrm{r}}=\mathrm{R}_{\mathrm{w}} \times \mathrm{f}_{\mathrm{r}} \times \mathrm{M}_{\mathrm{v}} \times \mathrm{g} \\
\mathrm{T}_{\mathrm{a}}=\mathrm{R}_{\mathrm{w}} \times \frac{\left(\mathrm{M}_{\mathrm{va}} \times \mathrm{C}_{\mathrm{x}} \times \mathrm{A}_{\mathrm{f}}\right)}{2} \times \mathrm{V}^{2} \\
\mathrm{~T}_{\mathrm{c}}=\mathrm{M}_{\mathrm{v}} \times \mathrm{g} \times \sin (\lambda)
\end{gathered}
$$

Where $\mathrm{s}$ is the dry friction coefficient, $\chi$. is the viscous friction coefficient, $\mathrm{k}$ is the fluid friction coefficient, $\lambda$ is the angle that the road makes with the horizontal, $\mathrm{M}_{\mathrm{va}}$ is the density of the air, $C_{x}$ is the aerodynamic drag coefficient, $r_{p}$ is a coefficient taking account of the mechanical losses in the motor and the transmission system, and $A_{f}$ is the vehicle frontal area. The phase current becomes: 


$$
I=\frac{T_{m}}{2 \times n \times N_{s} \times A \times B \times B_{g}}
$$

The dimensioning current is expressed as follows:

$$
I_{\text {dim }}=\frac{T_{\text {dim }}}{2 \times n \times N_{s} \times A \times B \times B_{g}}
$$

$\mathrm{T}_{\mathrm{dim}}$ is the dimensioning torque. This torque is found by the genetic algorithm method on a standardized circulation mission in order to not exceed the limiting temperatures and to minimize the motor mass.

Several methods were proposed to define dimensioning sizes of the motor-reducer torque, based on simplified statistical tools [9]. A first method is based on the determination of the effective torque for a circulation mission in order to take into account the thermal aspect [9]. A second more elaborate approach consists in defining zones of strong occurrences and to take the sizes resulting from these zones like dimensioning sizes. Finally, a last simpler method consists in dividing the torque-speed plan into 4 zones, and to take the gravity center of each zone then to consider the gravity center of these four points balanced by the number of each zone points as dimensioning point. These methods have the advantage of quickly providing useful sizes for dimensioning and simulation, nevertheless they do not take into account the problem of electric vehicle consumption minimization. For our approach, the dimensioning torque will be iteratively calculated by the genetic algorithms method in order to satisfy a global optimization of autonomy while respecting the dimensional thermal stresses relating to our application specified by the schedule of conditions. To guide the algorithm to converge towards a powerful solution and in order to limit the space of research, the motor dimensioning torque must satisfy the following condition extracted inequality:

$$
\begin{aligned}
& (1-\varepsilon) \times R_{w} \times\left(\frac{\frac{J}{R_{w}^{2}}+\frac{M_{v}}{r_{d}}}{t_{d}} \times V_{b}+\frac{M_{v} \times g \times \sin (\lambda)}{r_{d}}\right) \\
& \leq T_{d i m}(1+\varepsilon) \times R_{w} \times\left(\frac{\frac{J}{R_{w}^{2}}+\frac{M_{v}}{r_{d}}}{t_{d}} \times V_{b}+\frac{M_{v} \times g \times \sin (\lambda)}{r_{d}}\right)
\end{aligned}
$$

The adjustment coefficient of the torque $\varepsilon$ generally does not exceed 0.25 and will be adjusted by simulations of the propulsion system on normalised circulation missions.

\section{Motor Sizing}

The air-gap flux density is calculated for a maximal recovery position, or the magnet is in front of a main tooth. At this position the air-gap flux density is maximal. The distribution of the field lines to the level of a pole is illustrated by the figure 2 :

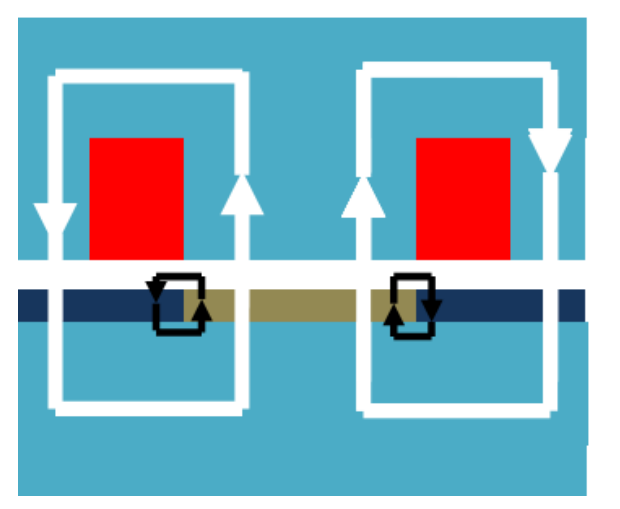

Figure 2. Flux lines distribution at maximal recovery position.

The flux decomposes itself in main flux assuring the traction of the rotor by interaction with the stator flux and in leakages flux between magnets.

As applying the Ampere theorem to the level of a stator pole, we can deduct the flux density due to the powering of a stator coil.

$$
\int_{\text {flux lines }} \overrightarrow{\mathrm{H}} \times \overrightarrow{\mathrm{dl}}=\frac{\mathrm{N}_{\mathrm{s}}}{2} \times \mathrm{I}_{\max }=2 \times\left(\mathrm{H}_{\mathrm{ri}} \times \mathrm{t}_{\mathrm{m}}+\mathrm{H}_{\mathrm{ri}} \times \mathrm{g}\right)
$$

Where $\mathrm{I}_{\max }$ is the maximal current feeding the motor, $\mathrm{H}$ is the magnetic field, $\mathrm{H}_{\mathrm{ri}}$ is the air-gap magnetic field, $\mathrm{t}_{\mathrm{m}}$ is the magnet thickness and $\mu_{0}$ is the air permeability.

$$
\mathrm{B}_{\mathrm{ri}}=\mu_{0} \times \mathrm{H}_{\mathrm{ri}}
$$

Where $B_{\mathrm{ri}}$ is the flux density in the air-gap due to the powering of stator coil.

$$
\operatorname{Bri}=\frac{\mu_{0}}{4} \times \frac{\mathrm{N}_{\mathrm{s}} \times \mathrm{I}_{\max }}{\mathrm{t}_{\mathrm{m}}+\mathrm{g}}
$$

While applying the Ampere theorem, we can deduct the magnet thickness imposing a fixed flux density in the different zones of the motor while disregarding the flux density due to the powering of the stator coils, since the flux must cross two times the air-gap thickness and magnet with permeability very close to the air permeability.

$$
\int_{\text {flux lines }} \overrightarrow{\mathrm{H}} \times \overrightarrow{\mathrm{dl}}=0=2 \times\left(\mathrm{H}_{\mathrm{m}} \times \mathrm{t}_{\mathrm{m}}+\mathrm{H}_{\mathrm{g}} \times \mathrm{g}\right)
$$

The air-gap flux density is linear according to the magnetic field for this working regime:

$$
\mathrm{B}_{\mathrm{g}}=\mu_{0} \times \mathrm{H}_{\mathrm{g}}
$$

While applying the flux conservation theorem to the level of the air-gap, we deduct the value of the air-gap flux density in function of the magnet flux density and the coefficient of the leakages flux.

$$
\mathrm{B}_{\mathrm{m}} \times \mathrm{S}_{\mathrm{m}} \times \mathrm{K}_{\mathrm{fu}}=\mathrm{B}_{\mathrm{g}} \times \mathrm{S}_{\mathrm{m}}
$$


The magnet flux density becomes:

$$
\mathrm{B}_{\mathrm{m}}=\frac{\mathrm{B}_{\mathrm{g}}}{\mathrm{K}_{\mathrm{fu}}}
$$

The magnet flux density is approached by the following linear equation:

$$
\mathrm{B}_{\mathrm{m}}=\mu_{0} \times \mu_{\mathrm{m}} \times \mathrm{H}_{\mathrm{m}}+\mathrm{B}_{\mathrm{r}}
$$

Where $\mu_{m}$ is the magnet's relative permeability, $B_{r}$ is the remanence.

From the equation (29), (30), (31) and (32), we deduct the magnet thickness fixing the air-gap flux density equal to $B_{g}$, :

$$
t_{m}=\mu_{m} \times \frac{B_{g}}{B_{r}-\frac{B_{g}}{K_{f u}}} \times g
$$

Where $\mathrm{K}_{\mathrm{fu}}<1$ is the magnet's leakage coefficient and $\mathrm{g}$ is the air-gap thickness. To avoid demagnetization, the phase currents must be lower then the demagnetization current $I_{d}[8]$ :

$$
I_{d}=\left(\frac{B_{r}-B_{\text {min }}}{\mu_{m}} \times t_{m}-B_{\text {min }} \times K_{f u} \times g\right) \times \frac{p}{2 \times \mu_{0} \times N_{s}}
$$

Where $B_{\min }$ is the minimum flux density allowed in the magnets and $\mu_{0}$ is the air permeability. The rotor yoke thickness $t_{\mathrm{ry}}$ and stator yoke thickness $t_{\mathrm{sy}}$ derive from the flux conservation [9]:

$$
\begin{aligned}
& t_{r y}=\frac{B_{g}}{B_{r y}} \times \frac{\operatorname{Min}\left(A_{t}, A_{m}\right)}{2 \times A} \times \frac{1}{K_{f u}} \\
& t_{\text {sy }}=\frac{B_{g}}{B_{\text {sy }}} \times \frac{\operatorname{Min}\left(A_{t}, A_{m}\right)}{2 \times A}
\end{aligned}
$$

Where $A_{t}$ is the tooth area, $A_{m}$ is the area of one magnet, $B_{\text {ry }}$ and $\mathrm{B}_{\mathrm{sy}}$ are respectively the flux densities in rotor and stator yokes. For the axial flux and trapezoidal wave-form motor configurations the slot height is [9]:

$$
\mathrm{h}_{\mathrm{s}}=\frac{3 \cdot 2 \cdot \mathrm{N}_{\mathrm{s}}}{2 \mathrm{~N}_{\mathrm{t}}} \frac{\mathrm{I}_{\mathrm{dim}}}{\delta} \frac{1}{\mathrm{~K}_{\mathrm{f}}} \frac{1}{\mathrm{~A}_{\mathrm{s}}}
$$

Where $N_{t}$ is the number of principal teeth, $\delta$ is the current density in slots, $K_{f}$ is the slot filling factor, $A_{s}$ is the slot width and $\mathrm{I}_{\mathrm{dim}}$ is the dimensioning current:

$$
\mathrm{I}_{\mathrm{dim}}=\frac{\mathrm{T}_{\mathrm{dim}}}{\mathrm{K}_{\mathrm{e}}}
$$

The slot width is expressed as follows:

$$
\mathrm{A}_{\mathrm{s}}=\mathrm{B} \times \operatorname{SIN}\left(\frac{1}{2} \times\left(\frac{2 \times \pi}{\mathrm{N}_{\mathrm{t}}}-\alpha \times \beta \times \frac{\pi}{\mathrm{p}} \times\left(1-\mathrm{r}_{\mathrm{did}}\right)\right)\right)
$$

Where $r_{\text {did }}$ is the ratio between the angular width of the inserted tooth and that of the principal tooth. This ratio is optimised by finite elements simulations in order to reduce the flux leakages and to improve the back E.m.f. wave-form. Optimisation problem

The optimization problem consists on the determination of the motor-converter sizes minimizing its mass and the electric vehicle consumption, while respecting the technological constraints of the application.

The motor weight is expressed as follows:

$$
\mathrm{W}_{\mathrm{m}}=\mathrm{W}_{\mathrm{sy}}+\mathrm{W}_{\mathrm{t}}+\mathrm{W}_{\mathrm{c}}+\mathrm{W}_{\mathrm{ry}}+\mathrm{W}_{\mathrm{m}}
$$

For the axial flux configurations the weight of stator yoke $\mathrm{W}_{\text {sy }}$, tooth $\mathrm{W}_{\mathrm{t}}$, copper $\mathrm{W}_{\mathrm{c}}$, rotor yoke $\mathrm{W}_{\mathrm{ry}}$, and magnets $\mathrm{W}_{\mathrm{m}}$ are expressed as follows:

$$
\begin{gathered}
\mathrm{W}_{\mathrm{sy}}=\mathrm{n} \times \mathrm{d} \frac{\pi}{4} \times\left(\mathrm{D}_{\mathrm{e}}^{2}-\mathrm{D}_{\mathrm{i}}^{2}\right) \times \mathrm{t}_{\mathrm{sy}} \\
\mathrm{W}_{\mathrm{t}}=\mathrm{n} \times \mathrm{d} \times \mathrm{N}_{\mathrm{t}} \times \mathrm{A}_{\mathrm{t}} \times \mathrm{h}_{\mathrm{s}} \\
\mathrm{W}_{\mathrm{c}}=3 \times \mathrm{n} \times \mathrm{N}_{\mathrm{s}} \times \mathrm{L}_{\mathrm{sp}} \times \frac{\mathrm{I}_{\mathrm{dim}}}{\delta} \times \mathrm{d}_{\mathrm{c}} \\
\mathrm{W}_{\mathrm{ry}}=\pi \times\left(\left(\frac{\mathrm{D}_{\mathrm{e}}}{2}\right)^{2}-\left(\frac{\mathrm{D}_{\mathrm{i}}}{2}\right)^{2}\right) \times \mathrm{t}_{\mathrm{ry}} \times \mathrm{d} \\
\mathrm{W}_{\mathrm{m}}=2 \times \mathrm{n} \times \mathrm{p} \times \mathrm{A}_{\mathrm{m}} \times \mathrm{t}_{\mathrm{m}} \times \mathrm{d}_{\mathrm{m}}
\end{gathered}
$$

Where $d$ is the density of the metal sheet, $d_{c}$ is the density of copper, $d_{m}$ is the magnet density, $A_{a}$ is the magnet angular width, $A_{d}$ is the angular width of principal teeth and $A_{e}$ is the slot angular width.

For the trapezoidal wave-form configurations, the copper losses are expressed by the following relation:

$$
P_{c}=2 \times R \times I^{2}
$$

The phase resistance is given by the following expression:

$$
\mathrm{R}=\mathrm{r}_{\mathrm{cu}}\left(\mathrm{T}_{\mathrm{b}}\right) \times \frac{\mathrm{N}_{\mathrm{s}} \times \mathrm{L}_{\mathrm{sp}}}{\mathrm{S}_{\mathrm{c}}}
$$

Where $r_{c u}$ is the copper receptivity, $\mathrm{L}_{\mathrm{sp}}$ is the average length of spire, $\mathrm{T}_{\mathrm{b}}$ is the copper temperature and $\mathrm{S}_{\mathrm{c}}$ is the active section of one conductor:

$$
\mathrm{S}_{\mathrm{c}}=\frac{\mathrm{I}_{\mathrm{dim}}}{\delta}
$$

The iron losses are expressed by the following relation [14], [15], [16], [17], [18], [19]:

$$
\mathrm{P}_{\mathrm{fer}}=\mathrm{C} \times \mathrm{f}^{1.5} \times\left(\mathrm{n} \times \mathrm{W}_{\mathrm{t}} \times \mathrm{B}_{\mathrm{g}}^{2}+\mathrm{n} \times \mathrm{W}_{\mathrm{sy}} \times \mathrm{B}_{\mathrm{sy}}^{2}\right)
$$

Where $\mathrm{c}$ is the core loss, $\mathrm{f}$ is the motor powering frequency, $\mathrm{W}_{\mathrm{t}}$ is the teeth weight, $\mathrm{W}_{\mathrm{sy}}$ is the stator yoke weight, $\mathrm{B}_{\mathrm{g}}$ is the 
ai-rgap flux density and $\mathrm{B}_{\mathrm{sy}}$ is the flux density in stator yoke. The mechanical losses are expressed by the following relation [11]:

$$
\mathrm{P}_{\mathrm{m}}=\left(\mathrm{T}_{\mathrm{b}}+\mathrm{T}_{\mathrm{vb}}+\mathrm{T}_{\mathrm{fr}}\right) \times \Omega
$$

Where $\Omega$ is the angular speed of the electric motor.

The losses in the static converter are nearly hopeless, they are not held in account in the model of power train losses calculation.

Since always two phases are feeding, the losses in the battery are expressed by the following expression:

$$
\mathrm{P}_{\mathrm{b}}=2 \times \mathrm{R}_{\text {batt }} \times \mathrm{I}_{\mathrm{b}}^{2}
$$

Where $\mathrm{R}_{\text {batt }}$ is the internal resistance of the battery.

The power train losses is expressed consequently by the next equation:

$$
\mathrm{P}_{\mathrm{ptl}}=\mathrm{P}_{\mathrm{c}}+\mathrm{P}_{\mathrm{fer}}+\mathrm{P}_{\mathrm{m}}
$$

The model of the power train losses is coupled to the electric vehicle power train model. This structure of this model is illustrated by the figure 3 .

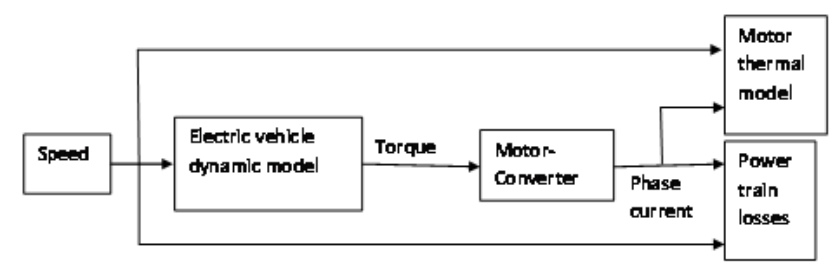

Figure 3. Electric vehicle power train model.

\section{Genetic Algorithms Optimization of the Motor Mass and the Power Train Losses}

The function to optimize is expressed by the following expression:

$$
\mathrm{F}_{\mathrm{o}}=\mathrm{W}_{\mathrm{m}}+\mathrm{a} \mathrm{P}_{\mathrm{ptl}}
$$

Where " $\mathrm{a}$ " is a coefficient fixing the influence degree of $\mathrm{P}_{\mathrm{ptl}}$ at the global objective function compared to $\mathrm{W}_{\mathrm{m}}$. Indeed, "a" brings closer the value of $\left(\mathrm{a} \mathrm{P}_{\mathrm{ptl}}\right)$ to the value of $\mathrm{W}_{\mathrm{m}}$.

The optimisation problem consists in optimising the $\mathrm{F}_{\mathrm{o}}$ with respect to the problem constraints. In fact, Genetic Algorithms (GAs) are used to find optimal values of the switched frequency $f_{s w}$, radius of the wheel in meters $R_{w}$, the gear ratio $\mathrm{r}_{\mathrm{d}}$, The adjustment coefficient of the torque $\varepsilon$, the internal diameter $D_{i}$, the external diameter $D_{e}$, the flux density in the air-gap $B_{g}$, the current density in the coils $\delta$, the flux density in the rotor yoke $\mathrm{B}_{\mathrm{ry}}$, the flux density in the stator yoke $\mathrm{B}_{\mathrm{sy}}$ and the number of phase spires $\mathrm{N}_{\mathrm{s}}$ [14], [15], [16], [17], [18], [19].

The beach of variation of each parameter $x i \in\left(f_{s w}, R_{w}, r_{d}\right.$, $\varepsilon, \mathrm{D}_{\mathrm{i}}, \mathrm{D}_{\mathrm{e}}, \mathrm{B}_{\mathrm{g}}, \delta, \mathrm{B}_{\mathrm{ry}}, \mathrm{B}_{\mathrm{sy}}, \mathrm{Ns}$ ) must respect the following constraint: $\mathrm{x}_{\text {imin }} \leq \mathrm{x}_{\mathrm{i}} \leq \mathrm{x}_{\mathrm{imax}}$. The values of the lower limit $\mathrm{x}_{\mathrm{imin}}$ and the upper limit $x_{\text {imax }}$ are established following technological, physical and expert considerations, for example:

- The internal and external diameter of the motor is delimited by the space reserved for the motor.

$$
\left\{\begin{array}{c}
\text { maximise }\left(\mathrm{F}_{\mathrm{o}}\right) \\
\text { with : } \\
500 \leq \mathrm{f}_{\mathrm{sw}} \leq 5000(\mathrm{~Hz}) \\
0.25 \leq \mathrm{R}_{\mathrm{w}} 0.35(\mathrm{~m}) \\
1 \leq \mathrm{r}_{\mathrm{d}} \leq 8 \\
0 \leq \varepsilon \leq 0.25 \\
0.025 \leq \mathrm{D}_{\mathrm{i}} \leq 0.25(\mathrm{~m}) \\
0.26 \leq \mathrm{D}_{\mathrm{e}} \leq 0.5(\mathrm{~m}) \\
0.1 \leq \mathrm{B}_{\mathrm{g}} \leq 1.04(\mathrm{~T}) \\
5 \leq \delta \leq 7\left(\mathrm{~A} / \mathrm{mm}^{2}\right) \\
0.1 \leq \mathrm{B}_{\mathrm{ry}} \leq 1.06(\mathrm{~T}) \\
0.1 \leq \mathrm{B}_{\mathrm{sy}} \leq 1.6(\mathrm{~T}) \\
10 \leq \mathrm{N}_{\mathrm{s}} \leq 1000 \\
\mathrm{r} \leq 10 \% \\
\mathrm{Udc} \leq 100(\mathrm{~V}) \\
\mathrm{I} \leq \mathrm{I}_{\mathrm{d}}(\mathrm{A}) \\
\mathrm{T}_{\mathrm{a}} \leq 50\left({ }^{\circ} \mathrm{C}\right) \\
\mathrm{T}_{\mathrm{b}} \leq 90\left({ }^{\circ} \mathrm{C}\right)
\end{array}\right\}
$$

Where $T_{a}$ and $T_{b}$ are respectively the magnets and the coils temperatures.

The $F_{o}$ model is coupled to a program of optimization by the method of the genetic algorithm. The progress of the program of optimization of the $\mathrm{F}_{\mathrm{o}}$ with constraints is described by this organization diagram (figure 4) [14], [15], [16], [17], [18]:

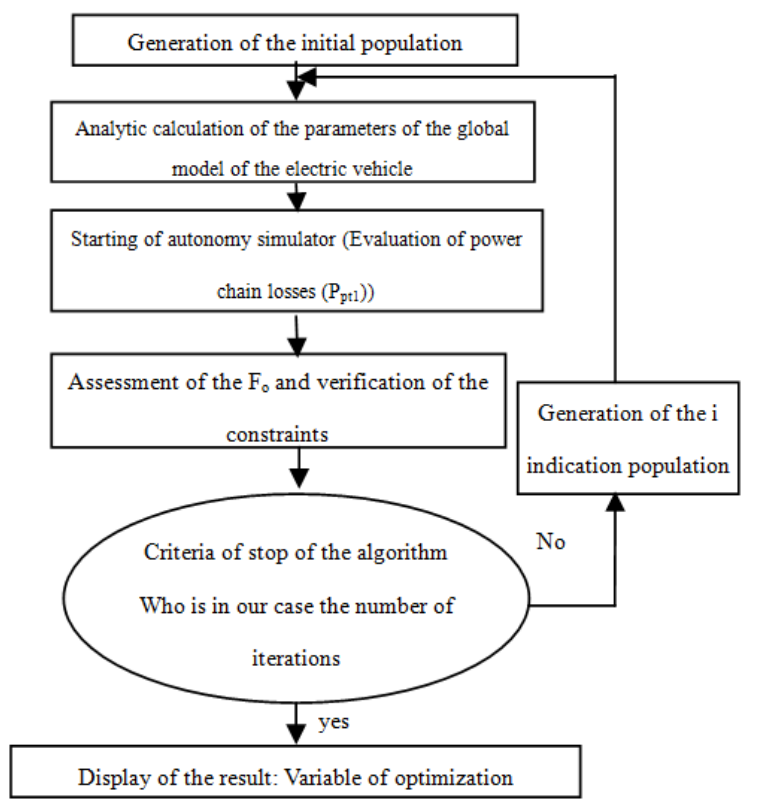

Figure 4. Progress of the optimization program.

\section{Conclusion}

An analytical model dimensioning the whole motor converter is developed. This model is coupled to an 
optimization program in order to find the design and control parameters of the whole motor-converter minimizing the power train energy losses and the electric vehicle cost. This study encourages the manufacture procedure of electric vehicles in big series [9], [14], [15], [16], [17], [18], [19].

\section{References}

[1] Chaithongsuk, S., Nahid-Mobarakeh, B., Caron, J., Takorabet, N., \& Meibody-Tabar, F. : Optimal design of permanent magnet motors to improve field-weakening performances in variable speed drives. Industrial Electronics, IEEE Transactions on, vol 59 no 6, p. 2484-2494, 2012.

[2] Rahman, M. A., Osheiba, A. M., Kurihara, K., Jabbar, M. A., Ping, H. W., Wang, K., \& Zubayer, H. M.: Advances on single-phase line-start high efficiency interior permanent magnet motors. Industrial Electronics, IEEE Transactions on, vol 59 no 3, p. 1333-1345, 2012.

[3] C.C Hwang, J.J. Chang : Design and analysis of a high power density and high efficiency permanent magnet DC motor, Journal of Magnetism and Magnetic Materials, Volume 209, Number 1, February 2000, pp. 234-236(3)-Publisher: Elsevier.

[4] MI. Chunting CHRIS: Analytical design of permanent-magnet traction-drive motors" Magnetics, IEEE Transactions on Volume 42, Issue 7, July 2006 Page(s):1861 - 1866 Digital Object Dentifier 10.1109/TMAG.2006.874511.

[5] S.TOUNSI, R.NÉJI, F.SELLAMI: Conception d'un actionneur à aimants permanents pour véhicules électriques, Revue Internationale de Génie Électrique volume 9/6 2006 pp.693-718.

[6] Sid Ali. RANDI: Conception systématique de chaînes de traction synchrones pour véhicule électrique à large gamme de vitesse. Thèse de Doctorat 2003, Institut National Polytechnique de Toulouse, UMRCNRS № 5828.

[7] C. PERTUZA: Contribution à la définition de moteurs à aimants permanents pour un véhicule électrique routier. Thèse de docteur de 1'Institut National Polytechnique de Toulouse, Février 1996.

[8] S. TounsI, R. NEJI and F. SELLAmI: Mathematical model of the electric vehicle autonomy. ICEM2006 (16th International Conference on Electrical Machines), 2-5 September 2006 Chania-Greece, CD: PTM4-1.

[9] R. NEJI, S. TOUNSI, F. SELLAMI: Contribution to the definition of a permanent magnet motor with reduced production cost for the electrical vehicle propulsion. Journal European Transactions on Electrical Power (ETEP), Volume 16, issue 4, 2006, pp. 437-460.
[10] P. BASTIANI: Stratégies de commande minimisant les pertes d'un ensemble convertisseur machine alternative : application à la traction électrique. Thèse INSA 01 ISAL 0007, 2001.

[11] G. Henriot: Traité théorique et pratique des engrenages : théorie et technologie 1. tome 1 Edition Dunod 1952.

[12] D-H. Cho, J-K. Kim, H-K. Jung and C-G. Lee: Optimal design of permanent-magnet motor using autotuning Niching Genetic Algorithm, IEEE Transactions on Magnetics, Vol. 39, No. 3, May 2003.

[13] Islam, M. S., Islam, R., \& Sebastian, T.: Experimental verification of design techniques of permanent-magnet synchronous motors for low-torque-ripple applications. Industry Applications, IEEE Transactions on, vol 47 no 1, p. 88-95, 2011.

[14] Parasiliti, F., Villani, M., Lucidi, S., \& Rinaldi, F. : Finite-element-based multiobjective design optimization procedure of interior permanent magnet synchronous motors for wide constant-power region operation. Industrial Electronics, IEEE Transactions on, vol 59 no 6, p. 2503-2514, 2012.

[15] Mahmoudi, A., Kahourzade, S., Rahim, N. A., \& Ping, H. W.: Improvement to performance of solid-rotor-ringed line-start axial-flux permanent-magnet motor. Progress In Electromagnetics Research, 124, p. 383-404, 2012.

[16] Duan, Y., \& Ionel, D. M.: A review of recent developments in electrical machine design optimization methods with a permanent-magnet synchronous motor benchmark study. Industry Applications, IEEE Transactions on, vol 49 no 3, p. 1268-1275, 2013.

[17] Liu, G., Yang, J., Zhao, W., Ji, J., Chen, Q., \& Gong, W.: Design and analysis of a new fault-tolerant permanent-magnet vernier machine for electric vehicles. Magnetics, IEEE Transactions on, vol 48 no 11, p. 4176-4179, 2012.

[18] Lee, S., Kim, K., Cho, S., Jang, J., Lee, T., \& Hong, J.: Optimal design of interior permanent magnet synchronous motor considering the manufacturing tolerances using Taguchi robust design. Electric Power Applications, IET, vol 8 no 1, 23-28, 2014.

[19] TOUNSI, R. NEJI and F. SELLAMI : Electric vehicle control maximizing the autonomy: 3rd International Conference on Systems, Signal \& Devices (SSD’05), SSD-PES 102, 21-24 March 2005, Sousse, Tunisia. 